\title{
Modificación de una técnica de muestreo para mejorar la recuperación de Vibrio cholerae en aguas superficiales y residuales
}

\author{
Edgar Podlesky¹, Omayda Cárdenas²
}

\section{Resumen}

Para mejorar la eficiencia en la recuperación de $V$. cholerae en aguas, se modificó el hisopo de Moore incrementando su área de muestreo. El hisopo se ensayó en concentraciones de $V$. cholerae 01 y no 01 de $7,5 \times 10^{3}, 1,5 \times 10^{4}, 3,0 \times 10^{4}$ y $7,5 \times 10^{4}$ unidades formadoras de colonias (UFC) por mililitro tanto en aguas superficiales como residuales bajo dos modelos: dinámico, con el agua en continuo movimiento, y, estático, con el agua quieta. Los ensayos se realizaron en acuarios de vidrio de 20 litros tomándose muestras a las $12,24,36$ y 48 horas y cultivándose en agar BHI y TCBS.

La recuperación del Vibrio fue del 99,4\% (174/175), en aguas superficiales y del $100 \%$ (188/188), en aguas residuales cuando se cultivaron en agar BHI. La positividad en agar TCBS fue del $60 \%(105 / 175)$, en aguas superficiales y del $92,6 \%(174 / 188)$ y en aguas residuales.

Para el total de las muestras estudiadas, la capacidad de recuperación del hisopo fue del 99,7\% (362/363), en agar BHI y del 76,3\% (279/363) en agar TCBS.

El tiempo óptimo de muestreo fue de 24 horas.

\section{Summary}

To improve retrieval of Vibrio cholerae from fresh and sewage water, a new design of the Moore swab, increasing its sampling area several-fold, was tested.

The new swab was exposed to concentrations of $7.5 \times 10^{3}, 1.5 \times 10^{4}, 3.0 \times 10^{4}$ and $7.5 \times 10^{4}$ colony forming units (CFU) of Vibrio cholerae $\mathrm{O} 1$ and no 01 in trials involving fresh as well as sewage water, using two models: dynamic, water in constant movement, and static, being still water. 20 -liter glass containers were used to run the assays in samples being taken at $12,24,36$ and 48 hours. Brain-heart infusion ( $\mathrm{BHI}$ ) and thiosulfate-citratebile-sucrose (TCBS) were used as growing media.

The new swab retrieved $99.4 \%(174 / 175)$, of $V$. cholerae from fresh water and $100 \%$ $(188 / 188)$ from sewage water when grown on $\mathrm{BHI}$, in both models. On TCBS, $V$. cholerae was positive in $60 \%(105 / 174)$ of the samples for fresh water and $92.6 \%(174 / 188)$, for sewage water.

Overall, retrieval on $\mathrm{BHI}$ was $99.7 \%$ (362/363), and $76.3 \%(279 / 363)$ on TCBS. The best sampling time was established at 24 hours.

Coordinador de Investigación, Laboratorio de Salud Ambiental, INS.

2 Bacterióloga, Laboratorio de Salud Ambiental, INS. 
Vibrio cholerae, al igual que otros miembros de la familia Vibrionaceae, tiene su hábitat natural en el agua (1).

Comúnmente, la detección de contaminantes químicos y biólogicos se realiza analizando muestras puntuales o muestras compuestas de agua. Sin embargo, las muestras puntuales son poco representativas y las compuestas son dispendiosas de recolectar requiriendo normalmente mayores recursos humanos, de materiales y logísticos que lo hace poco costo-efectivo.

Dado que las descargas de los contaminantes se realiza de manera intermitente, es siempre deseable establecer un sistema de muestreo continuo de la fuente.

Para el muestreo de microorganismos en aguas, se han venido utilizando diferentes modalidades de hisopos que se sumergen en la fuente durante el tiempo deseado y luego se cultivan en medios apropiados.

B.B. Moore introdujo el uso de hisopos de gasa para el aislamiento de microorganismos entéricos en agua. Fueron fabricados con gasa de $60 \times 15$ $\mathrm{cm}$, doblándola varias veces hasta formar una almohadilla compacta $(2,3)$ (figura 1).

T.J. Barret y S. Giono emplearon rollos cilíndricos de gasa de longitud variable para el aislamiento de $V$. cholerae 01 en sistemas de alcantarillado en Estados Unidos (3-5) (figuras 2 y 3). Otra versión de la almohadilla de Moore fue utilizada por M. Isaacson en Suráfrica, para la detección de $V$. cholerae en aguas residuales $(6,7)$.

En la epidemia de cólera de Perú, se utilizaron bolsas de gasa de $10 \times 5 \mathrm{~cm}$ rellenas de algodón, con una pesa en la parte inferior del hisopo para mantenerlo sumergido en la fuente $(7,8)$ (figura 4). W.M. Spira construyó filtros con botellas plásticas con gasa como material filtrante para muestrear agua estancada (9).

Los hisopos tipo almohadilla se utilizaron en Colombia durante la epidemia de cólera para detectar Vibrio en aguas de mar y efluentes hospitalarios con resultados poco satisfactorios, pues, no se obtuvo un aislamiento eficiente del microorganismo (10). Este hecho motivó el presente estudio, bajo la premisa de que un incremento substancial en el área de muestreo del hisopo, mejoraría la captación y retención de Vibrio, para su posterior identificación en el laboratorio.

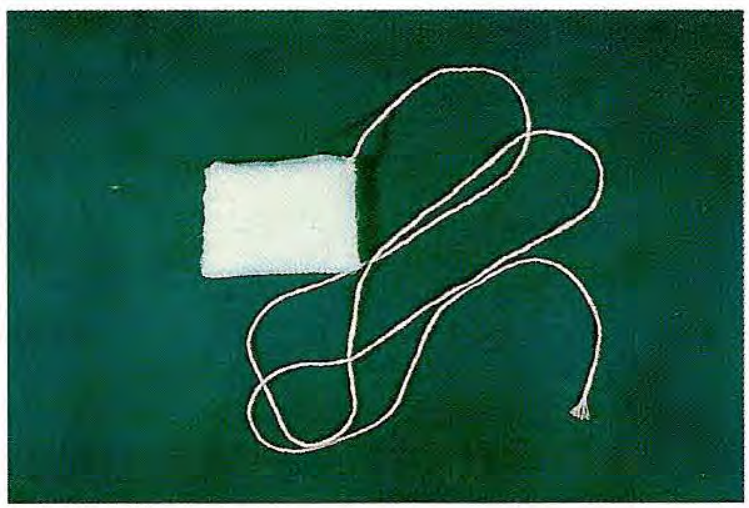

Figura 1. Hisopo de Moore.
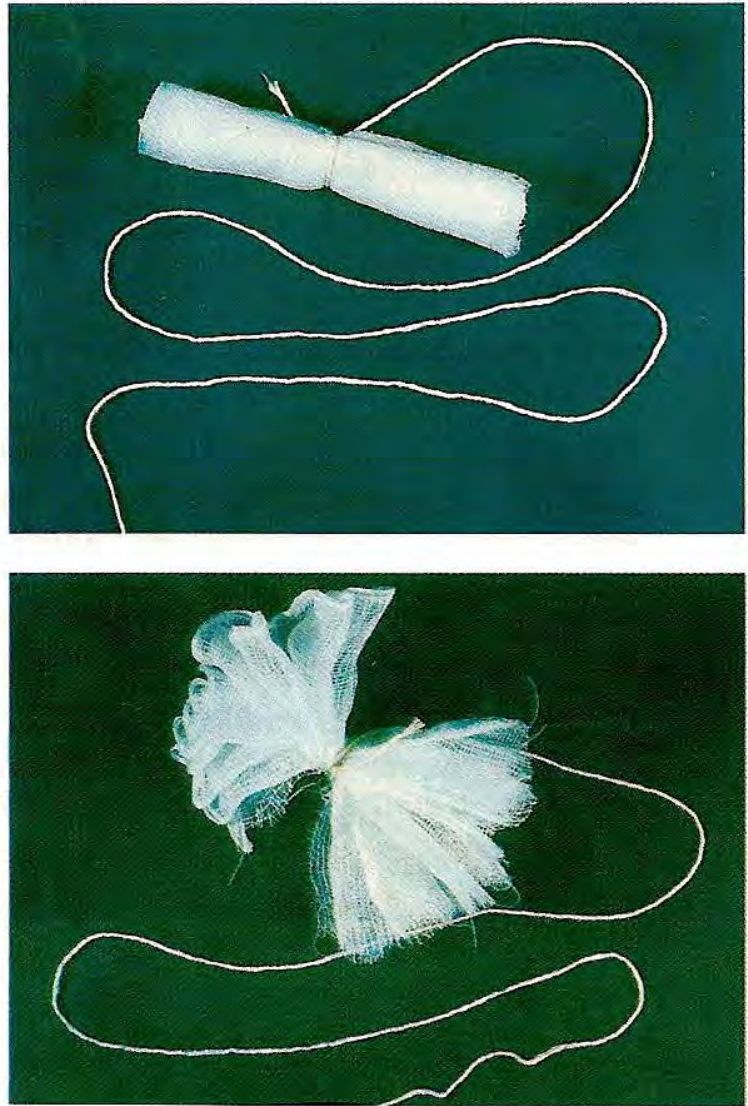

Figuras 2 y 3 . Hisopo Barret-Giono. 


\section{Materiales y métodos}

Fabricación del hisopo: para aumentar la superficie de muestreo del hisopo, se cortaron piezas de gasa de $45 \mathrm{~cm}$ de ancho por $60 \mathrm{~cm}$ de largo, doblándola a la mitad longitudinalmente y tres veces consecutivas a lo ancho, cortando en cada costado y quedando tiras de $30 \mathrm{~cm}$ de largo por $5 \mathrm{~cm}$ de ancho, aproximadamente, atándose el extremo superior con una cuerda (figura 5).

El hisopo se envolvió en papel Kraft y se esterilizó en autoclave a $121^{\circ} \mathrm{C}, 15 \mathrm{PSI}$ durante $20 \mathrm{~m}$.

Muestras: se utilizó agua del río San Francisco como fuente de agua superficial y aguas negras de la planta de bombeo El Salitre, como fuente de aguas residuales. Las características fisicoquímicas y bacteriológicas de cada fuente fueron determinadas antes de los ensayos.

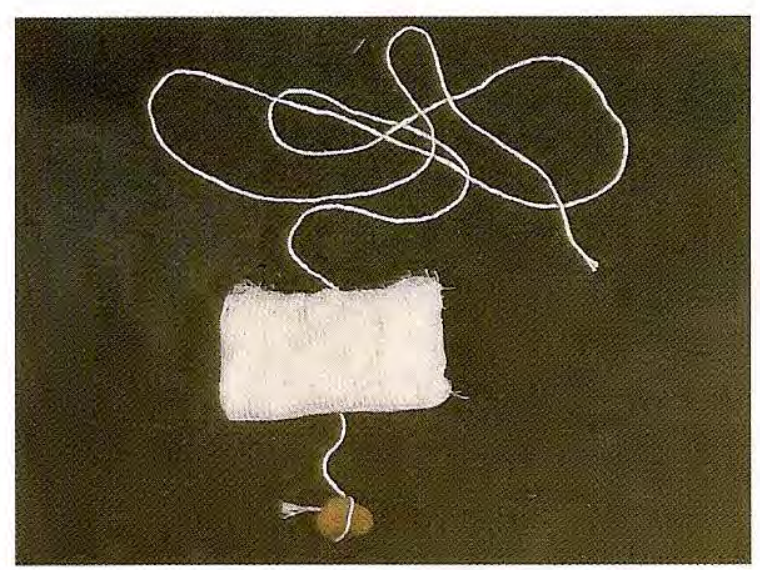

Figura 4. Hisopo Perú.

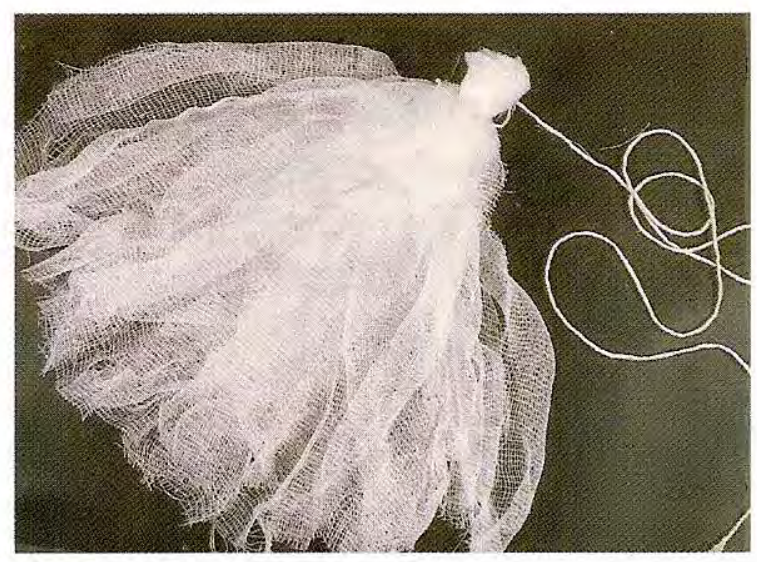

Figura 5. Modificación de los autores.
Diseño experimental: las dos clases de agua se estudiaron bajo dos modelos: a) dinámico, agua en movimiento para simular una corriente de agua, $y, b)$ estática para simular agua almacenada o estancada. Los ensayos se realizaron en acuarios de vidrio utilizando 20 litros de agua en cada ensayo.

Para simular el agua en movimiento, se utilizó un motor de dos salidas con rueda y mangueras de aireación. En el modelo estático no se utilizaron estos accesorios.

Cepas: se utilizaron cepas puras de $V$. cholerae 01 y no 01 tomadas en la fase logarítmica de crecimiento.

Concentraciones ensayadas: considerando que, bajo condiciones normales, la dosis oral infectante de $V$. cholerae en individuos sanos no aclorhídricos está en el orden de $1 \times 10^{8}$ a $1 \times 10^{10}$ microorganismos $(7,11-14)$, se ensayaron concentraciones finales de $7,5 \times 10^{3}, 1,5 \times 10^{4}, 3,0 \times 10^{4}$ y $7,5 \times 10^{4}$ unidades formadoras de colonias por mililitro (UFC/mL) partiendo de turbiedades correspondientes a los tubos número $0,5,1,0,2,0$ y 5,0 , respectivamente, de la escala de McFarland (15).

Tiempo de muestreo: se estudiaron tiempos de $12,24,36$ y 48 horas.

Enriquecimiento: cumplido el tiempo de muestreo, el hisopo se resuspendió en $200 \mathrm{~mL}$ de agua peptonada alcalina (APA), $\mathrm{pH} 8,9 \pm 0,3$ y se incubó a $35 \pm 2^{\circ} \mathrm{C}$ por $6 \mathrm{~h}$.

Identificación: cumplido el tiempo de preenrriquecimiento, se tomó un inóculo con asa de la superficie del APA y se sembró por agotamiento en agar infusión cerebro-corazón (BHI) y en agar tiosulfato-citrato-sales biliares-sacarosa (TCBS), incubándose a $35 \pm 2{ }^{\circ} \mathrm{C}$ por 18 a $24 \mathrm{~h}$. Los ensayos se realizaron por triplicado.

A las colonias sugestivas de $V$. cholerae en agar $\mathrm{BH}$, se les practicaron las pruebas de oxidasa y cuerda. Las colonias cuerda y oxidasa positivas se confirmaron a través de pruebas bioquímicas y serológicas.

A las colonias con características morfológicas sugestivas de $V$. cholerae se les realizó un sub- 


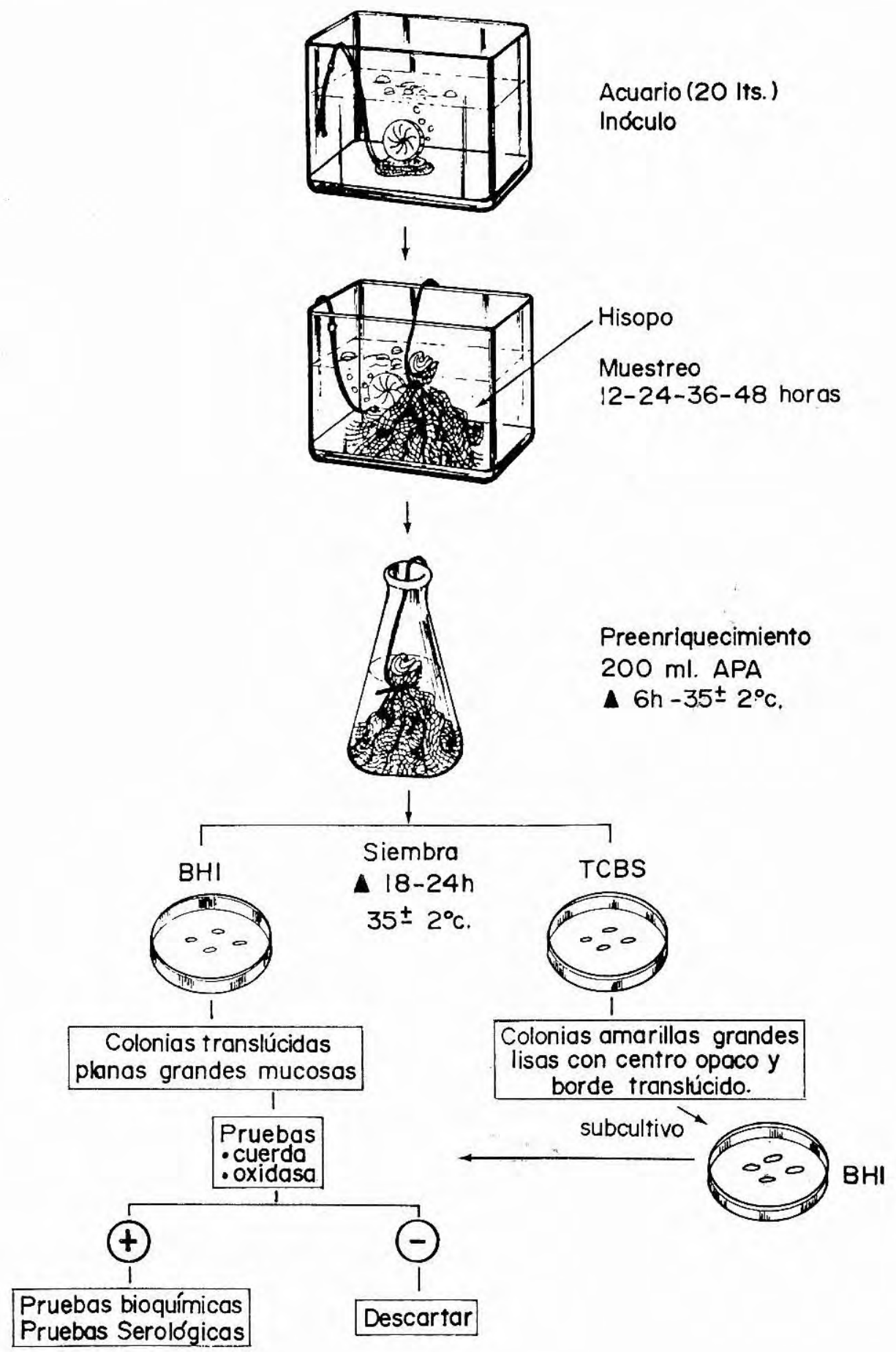

Figura 6. Esquema para la detección de Vibrio choleraecon hisopo de Moore modificado en aguas superficiales y residuales. 
cultivo en agar BHI. El diagrama de todo el procedimiento se presenta en la figura 6 .

Interpretación de resultados: el crecimiento se calificó mediante conteo directo de las UFC típicas de $V$. cholerae en cada uno de los medios utilizando la siguiente escala:

- Negativo: no hubo crecimiento de UFC típicas de V. cholerae.

- Positivo: hubo crecimiento de UFC típicas de V. cholerae.

- Ocasional: 1 a 4 UFC

- Escaso: 5 a 20 UFC

- Moderado: 21 a 80 UFC

- Abundante: más de 80 UFC a incontable

Evaluación de eficiencia: se calificó con base en la capacidad mostrada por el hisopo para detectar $V$. cholerae en la concentración más baja y en el menor tiempo de muestreo, tanto en aguas superficiales como residuales en ambos modelos.

\section{Resultados}

Se realizaron un total de 363 ensayos, 175 en aguas superficiales y 188 en aguas residuales observándose resultados positivos en 362 $(99,7 \%)$ de los cultivos en $\mathrm{BHI}$ y $279(76,3 \%)$ en medio TCBS (tabla 1).

En aguas superficiales, el hisopo detectó $V$. cholerae en el $99,4 \%$ (174/175) de las pruebas cultivadas en agar BHI y $60 \%(105 / 175)$ en agar TCBS.

Para aguas residuales, el crecimiento fue $100 \%$ positivo (188/188) en agar BHI y $92,6 \%(174 / 188)$ en agar TCBS (tabla 1).

Con relación al tiempo de muestreo, se observó crecimiento a las $12 \mathrm{~h}$ en agar $\mathrm{BHI}$ en todas las concentraciones tanto en aguas superficiales como residuales, conformándose un gradiente con respecto a la concentración de los inóculos utilizados (figuras 7 y 8), presentándose el mejor crecimiento en aguas superficiales a las $24 \mathrm{~h}$ con descenso a las $36 \mathrm{~h}$ que fue más marcado a las $48 \mathrm{~h}$ (figura 7).

El mayor crecimiento para aguas residuales en BHI también se observó a las $24 \mathrm{~h}$ con tendencia a disminuir a las 36 y $48 \mathrm{~h}$ (figura 8 ).
No se obtuvo crecimiento con el inóculo de $7,5 \times 10^{3} \mathrm{UFC} / \mathrm{mL}$ para aguas superficiales en agar TCBS en ninguno de los tiempos de muestreo. Sin embargo, hubo crecimiento evidente para las demás concentraciones a partir de las $12 \mathrm{~h}$ de muestreo, obteniéndose el mejor crecimiento a las $24 \mathrm{~h}$ con un notorio descenso a partir de las 36 y $48 \mathrm{~h}$ (figura 9 ).

El crecimiento de $V$. cholerae en agar TCBS a partir de aguas residuales, se observó en todas las concentraciones, en todos los tiempos de muestreo, obteniéndose la mayor recuperación a las $24 \mathrm{~h}$ (figura 10).

En relación con la recuperación de los diferentes tipos de $V$. cholerae, el hisopo mostró igual eficiencia para $V$. cholerae 01 como para $V$. cholerae no 01 en las dos clases de aguas en ambos modelos (tabla 2).

Tabla 1. Recuperación de Vibrio cholerae en muestras de aguas superficiales y residuales.

\begin{tabular}{|c|c|c|c|c|c|c|}
\hline & & & \multicolumn{2}{|c|}{ BHI } & \multicolumn{2}{|c|}{ TCBS } \\
\hline Fuente & Lugar & Ensayos & $n(\%)$ & $\%$ & $n(\%)$ & $\%$ \\
\hline Superficiales & Río San Francisco & 175 & 174 & 99,4 & 105 & 60,0 \\
\hline Residuales & Planta EI Salitre & 188 & 188 & 100,0 & 174 & 92,6 \\
\hline Total & 2 & 363 & 362 & 99,7 & 279 & 76,3 \\
\hline
\end{tabular}

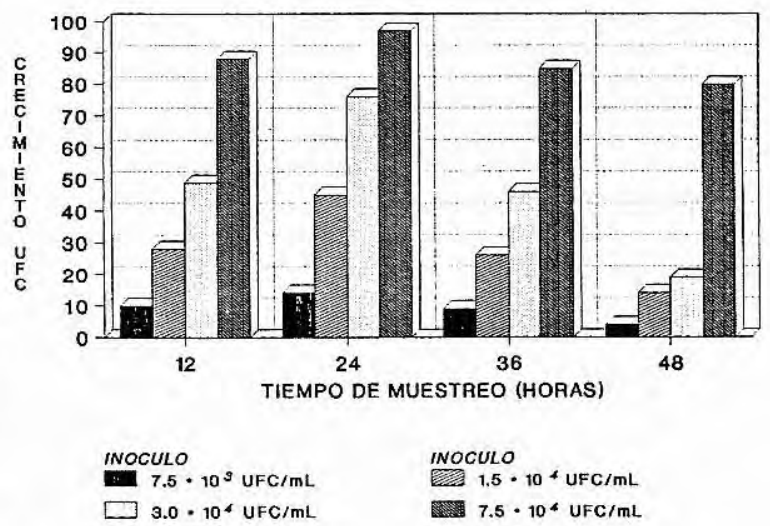

Figura 7. Aislamiento de $V$. cholerae en aguas superficiales, en agar BHI, según inóculo y tiempo de muestreo. 


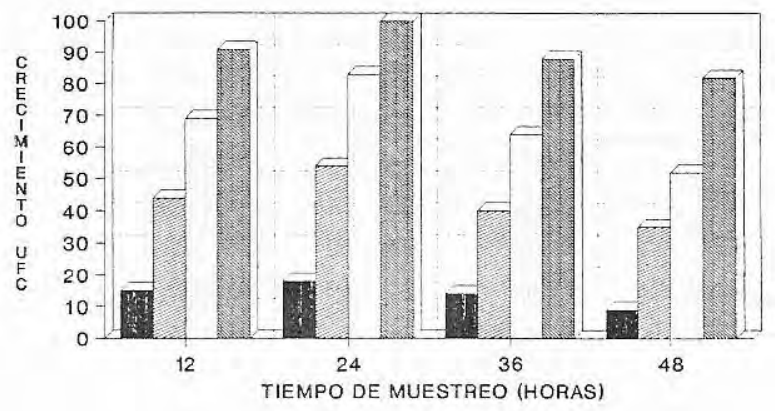

$$
\begin{aligned}
& \begin{array}{l}
\text { INOCULO } \\
7.5 \cdot 10^{3} \mathrm{UFC} / \mathrm{mL}
\end{array} \\
& \square .0 \cdot 10^{4} \mathrm{UFC} / \mathrm{mL} \text { 메 } 7.5 \cdot 10^{4} \mathrm{UFC} / \mathrm{mL}
\end{aligned}
$$

Figura 8. Aislamiento de $V$. cholerae en aguas residuales, en agar BHI, según inóculo y tiempo de muestreo.

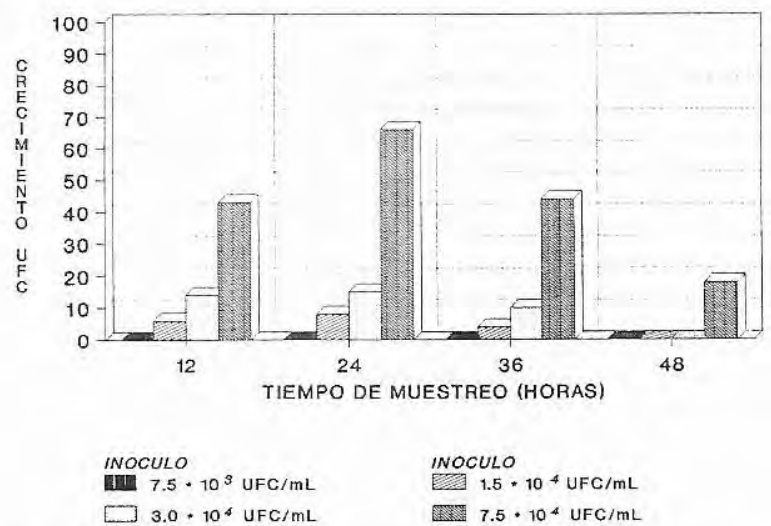

Figura 9. Aislamiento de $V$. cholerae en aguas superficiales, en agar TCBS, según inóculo y tiempo de muestreo.

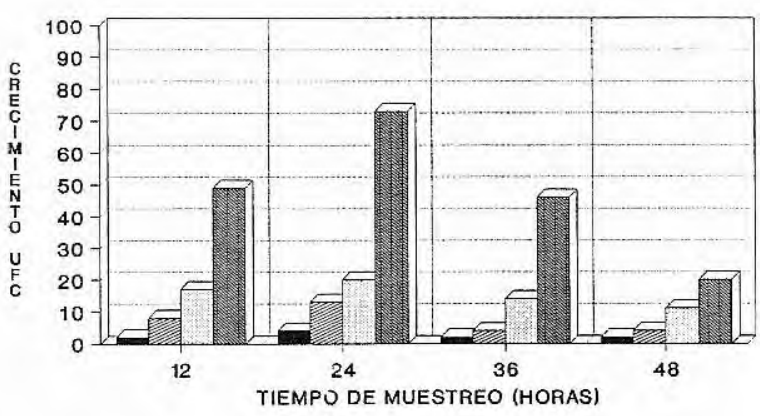

$$
\begin{aligned}
& \text { INOCULO } \\
& 7.5 \cdot 10^{3} \mathrm{UFC} / \mathrm{mL} \\
& 3.0 \cdot 10^{4} \mathrm{UFC} / \mathrm{mL}
\end{aligned}
$$

Figura 10. Aislamiento de $V$. cholerae en aguas residuales, en agar TCBS, según inóculo y tiempo de muestreo.

\section{Discusión}

Bajo las condiciones experimentales estudiadas, el hisopo modificado recuperó eficientemente ambas cepas de Vibrio cholerae, tanto en aguas superficiales como residuales. El hecho de que pudiera identificarse plenamente Vibrio a la concentración incial más baja ensayada (7.500 UFC/ $\mathrm{mL}$ ), podría ser de importancia en salud pública ya que el cólera se relaciona con poblaciones socialmente deprimidas con carencia de servicios públicos, incluyendo acueducto, que los obliga a mantener agua almacenada para bebida y preparación de alimentos.

El modelo estático ensayado simula una situación real en la cual un sistema de agua almacenada que fue contaminado con una concentración inicial baja $\left(7,5 \times 10^{3} \mathrm{UFC} / \mathrm{mL}\right)$, pudo ser detectada por el hisopo modificado dentro de un tiempo de muestreo corto (12 a $24 \mathrm{~h}$ ), lo cual ofrece a las autoridades de salud la oportunidad de implementar medidas tempranas y rápidas de prevención y control.

Dado que el modelo dinámico ensayado no refleja fielmente la situación de una corriente de agua contaminada con Vibrio, el tiempo de muestreo con el hisopo podría extenderse a 48 h o más para permitir una mejor acumulación de Vibrio en el hisopo en caso de que su circulación en aguas se esté dando a muy bajas concentraciones.

En lo que respecta a los medios de cultivo ensayados, Vibrio creció mejor en agar $\mathrm{BHI}$. Se destaca el hecho que, en este medio y no en TCBS, se pudo identificar plenamente Vibrio cholerae en la concentración inicial más baja ensayada $\left(7,5 \times 10^{3} \mathrm{UFC} / \mathrm{mL}\right)$. Es, además en el medio $\mathrm{BHI}$ y no en TCBS, donde se realizan las pruebas confirmatorias de Vibrio cholerae. A pesar de la conveniencia de seguir utilizando ambos medios, BHI y TCBS, para la identificación de Vibrio cholerae, es muy importante que el personal de laboratorio desarrolle una muy buena técnica para garantizar el aislamiento de las colonias en $\mathrm{BHI}$ ya que, a bajas concentraciones del microorganismo, es posible que no crezca en el agarTCBS, pero que sí lo haga en el BHI como sucedió en este estudio. 
Tabla 2. Recuperación de Vibrio cholerae en aguas superficiales y residuales, utilizando hisopo de Moore modificado.

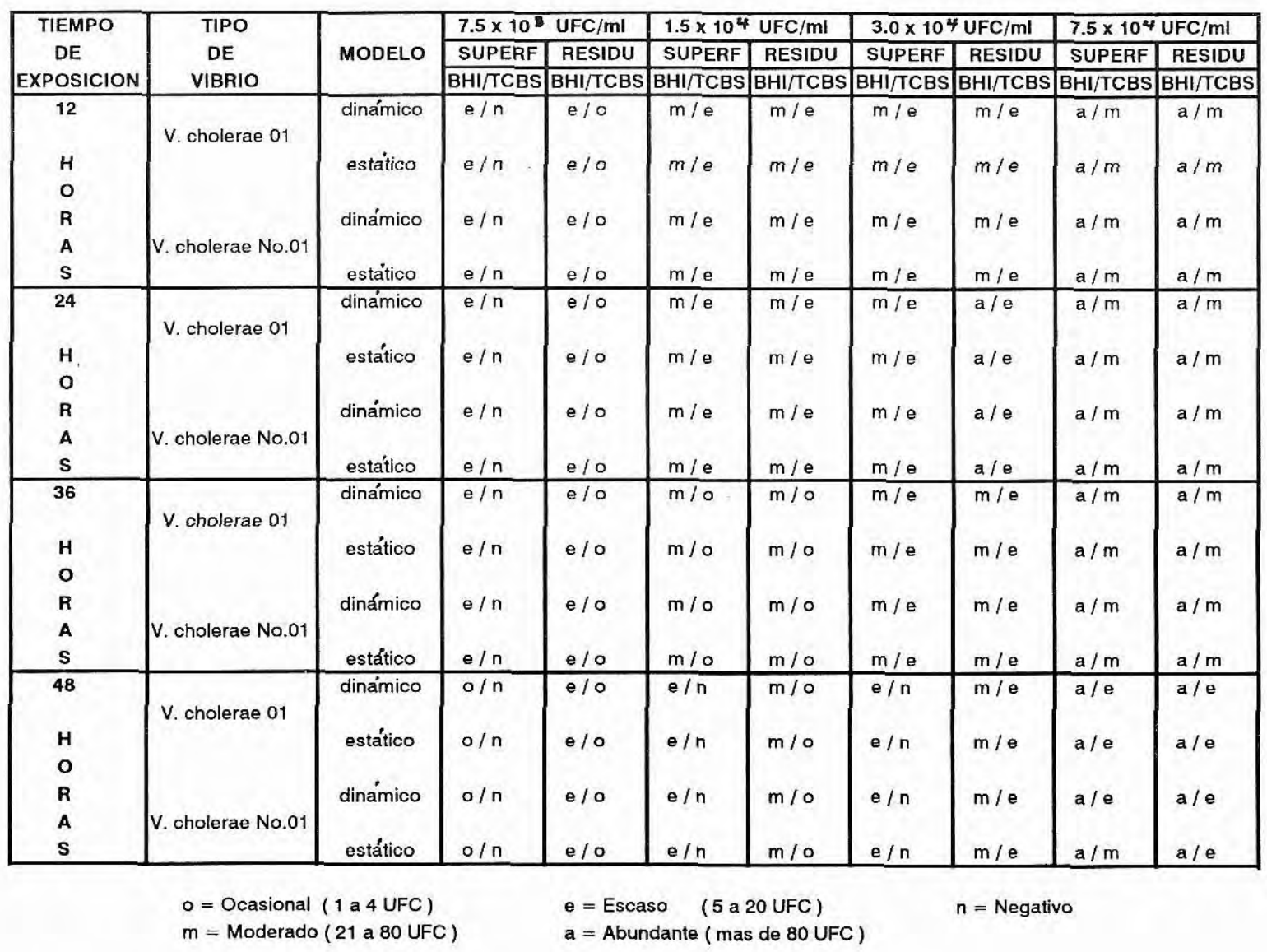

En conclusión, a pesar de que el hisopo modificado permite recuperar eficientemente Vibrio, el tiempo mínimo que debe transcurrir para su plena identificación es de $48 \mathrm{~h}$, si se considera un tiempo de muestreo de $24 \mathrm{~h}, 6 \mathrm{~h}$ de preenriquecimiento en APA y $18 \mathrm{~h}$ de incubación.

Sería conveniente validar nuevas tecnologías desarrolladas recientemente: pruebas inmunoenzimáticas, de fluorrescencia directa, etc., que aseguran poder identificar $V$. cholerae en aguas en tiempos de $15 \mathrm{~m}$ a $6 \mathrm{~h}$ dependiendo de la concentración de Vibrio en la fuente, y comprobar el costo-efectividad que podrían tener frente al procedimiento empleado en este estudio, lo que permitiría identificar la mejor propuesta para la eventual implantación de un sistema de monitoría permanente de $V$. cholerae en aguas superficiales y residuales.

\section{Agradecimientos}

Los autores agradecen a las estudiantes de bacteriología Liliana Rincón y Mónica Saavedra, por la colaboración en la realización de este trabajo. 


\section{Referencias}

1. Instituto de Nutrición de Centroamérica y Panamá, Centro para el Control de Enfermedades (CDC), Organización Panamericana de la Salud (OPS). Examen de muestras ambientales. Métodos de laboratorio para Vibrio cholerae. Guatemala, 1992:29-8.

2. Moore BB, Perry EL, Chard ST. A survey by the sewage swab method of latent enteric infection in an urban area. $J$ Hyg 1952;50:137-56.

3. Barret TJ, Blake PA, Morris GK, Puhr ND, Bradford HB, Wells JG. Use of Moore swabs for isolating Vibrio cholerae from sewage. J Clin Microbiol 1980;11:385-8.

4. Giono S, Gutiérrez L, Hinojosa AM. Hisopo de Moore para el muestreo de aguas negras o de corrientes para el aislamiento de Vibrio cholerae. Manual de procedimientos para aislamiento y caracterización de Vibrio choleraeO1. México, D.F., 1991;14-8.

5. Organización Panamericana de la Salud (OPS), Organización Mundial de la Salud (OMS). Aislamiento de Vibrio cholerae 01 de las muestras ambientales. Curso de métodos de laboratorio en el diagnóstico de Vibrio cholerae. Caracas, 1991:31-5.

6. Isaacson M. Practical aspects of a cholera surveillance programme. SAfr Med J 1975;49:1699-2.

7. Organización Panamericana de la Salud (OPS), Organización Mundial de la Salud (OMS), Programa de salud ambiental (CEPIS). Vibrio cholerae and cholera. El cólera. Lima, 1991:1-29.
8. Organización Mundial de la Salud (OMS), Organización Panamericana de la Salud (OPS). Salud ambiental y el cólera. Guía para la prevención y control del cólera. Quito, 1991:157-9.

9. Spira WM, Ahmed QS. Gauze filtration and enrichment procedures of recovery of Vibrio cholerae from contaminated waters. Appl Environ Microbiol 1981;42:730-3.

10. Podlesky E. Medidas de saneamiento ambiental para evitar la diseminación del cólera. Bogotá, D.C.: Manual INS, 1991:28.

11. Jawetz E, Adelberg E, Melnick J. Vibriones. Microbiología médica. México, D.F.: Editorial El Manual Moderno, 1987:262-6.

12. Paroid C, Olano J, Huaman R. Procedimientos para el diagnóstico de laboratorio del cólera. Manual de laboratorio cólera. Lima: Serie de Normas Técnicas No. 2, 1991:18-19.

13. Organización Panamericana de la Salud (OPS). Organización Mundial de la Salud (OMS). Riesgos de trasmisión del cólera por los alimentos. Washington, D.C.: Programa de Salud Pública Veterinaria, 1991:1-4.

14. Cash RA, Music SI, Libonati JP, Snyder MJ, Wenzel RP, Hornick RB. Response of man to infection with Vibrio cholerae. I. Clinical, serologic and bacteriologic responses to a known inoculum. J Infect Dis 1974;129:45-2.

15. Center for Disease Control and Prevention (CDC), National Center for Infectious Diseases (NCID). Preparation of media and reagents. Laboratory methods for the diagnosis of Vibrio cholerae. Washington, D.C.: NCID, 1993:125-6. 